\section{Abstract}

\title{
Herbicide tolerance of Euphorbia lagascae Spreng., (Euphorbiaceae)
}

\section{Richard J. Roseberg}

Dept. of Crop \& Soil Science, Oregon State University, Klamath Basin Research \& Extension Center, 6941 Washburn Way, Klamath Falls, OR 97603, USA.

Tel. 541-883-4590ＦAX 541-883-4596 email: richard.roseberg@oregonstate.edu

\section{Euphorbia lagascae Spreng., (Euphorbiaceae), (abbreviated EPHLA), has good potential to become an important crop and source of} epoxy fatty acids in semi-arid regions. Crop yield is enhanced with good weed control, and this study examined EPHLA's tolerance to several pre-plant incorporated (PPI), pre-emergence (PRE), and post-emergence (POST) herbicides, as well as seed and oil production factors. Preliminary tests were done in a greenhouse, and more involved studies were done in the field. The most promising PPI and PRE herbicides included benefin, ethalfluralin, trifluralin, and pendimethalin. Chloridazon and DCPA also gave reasonably good results, but rate and timing may be important when using these herbicides. Diuron and EPTC injured EPHLA and were poor herbicide candidates for EPHLA. The most promising POST herbicides included clopyralid, alachlor, acifluorfen, and chloridazon, to which EPHLA exhibited very good tolerance and very good to excellent yields. Oxyfluorfen and bromoxynil caused significant vegetative injury, but EPHLA produced good to excellent yields, suggesting that the herbicide injury was temporary. Bentazon and DCPA caused a moderately low degree of injury to EPHLA, which responded with a somewhat decreased seed yield, indicating that the 
effect of rate and timing may be important for these herbicides. Several POST herbicides, including metsulfuron, imazapyr,

imazethapyr, imazamox, ethofumesate, and dicamba, caused a low degree of visible injury to the EPHLA, but EPHLA seed yield was very low, suggesting that these herbicides injured EPHLA's reproductive processes. Picloram and 2,4-D caused severe damage or death to EPHLA. Because several PPI, PRE, and POST herbicides caused severe damage to EPHLA, they could be useful if EPHLA escaped cultivation to become a weed problem.

Keywords: Euphorbia lagascae, Herbicide, Seed yield, Oilseed, Vernolic acid, Oregon, Weeds.

\section{Introduction}

Euphorbia lagascae Spreng., (Euphorbiaceae) (hereafter abbreviated EPHLA in this paper), is a drought-tolerant native of southern Spain. Its seeds contain about 45 to $50 \%$ oil, of which 60 to $65 \%$ is a specific $\mathrm{C}_{18}$ epoxy fatty acid (EFA) known as vernolic acid (Kleiman et al., 1965; Vogel et al., 1993). Vernolic acid is produced by very few plants in nature, and of those, only EPHLA, Vernonia galamensis (Cass.) Less., (Asteraceae), and Stokesia laevis (Hill) Greene (Asteraceae), appear to have the potential to be domesticated for commercial agricultural production (Earle, 1970; Kleiman, 1990).

Early on, it was recognized that vernolic acid would be useful in the paint and coating industry as a drying solvent in alkyd resin paints and as a plasticizer or additive in polyvinyl chloride (PVC) resins (Carlson et al., 1981; Carlson and Chang, 1985). Coatings 
made with vernolic acid can greatly reduce volatile organic compound (VOC) emissions during drying that now occur with typical alkyd resins in conventional paints (Brownback and Glaser, 1992), thus reducing air pollution related to these VOCs.

Historically, EFA compounds have been made by chemically epoxidizing common oils such as soybean, rapeseed, linseed, and petroleum-derived oils (Carlson and Chang, 1985; Dierig and Thompson, 1993). However, such compounds are random mixtures of EFA chemical structures, with the epoxide group appearing on various carbon atoms in the chain, and thus may not perform as well as the more uniform EFA structure of EPHLA's vernolic acid for some applications (Trumbo, 1998; Turley et al., 2000). More details about EPHLA’s significance as a potential crop plant, its unique properties, crop status, current competitors, and likely uses in industry were described in our earlier reports (Roseberg, 1996; Roseberg and Shuck, 2009).

Despite the large benefits that could result from domestication of EPHLA as a crop, its development has been limited historically due to the seed-shattering trait that exists in all known wild populations. This, combined with the plant's indeterminate flowering and seed production pattern, ensures that only a small fraction of the potential seed yield is mature and harvestable at any given time for wild types. In the 1990s, synthetically mutagenized seeds that produce plants with a non-shattering seed habit were successfully developed (Pascual-Villalobos et al., 1994). This non-shattering trait has been inherited in subsequent generations, allowing field research on EPHLA’s agronomic crop requirements to occur using seed descended from this original mutagenized seed source. 
We have studied various aspects of EPHLA crop management between 1995 and 2012 in years when funding allowed. These studies were conducted primarily at the Southern Oregon Research and Extension Center (SOREC), near Medford, Oregon, or at the Klamath Basin Research and Extension Center (KBREC), near Klamath Falls, Oregon, both agricultural research stations operated by Oregon State University in SW Oregon. A production problem common to all existing or potential crops is weed competition and control. Our studies have suggested that once established, EPHLA competes well against many weeds in this region's semi-arid climate, but that weed competition can be severe for several weeks following germination. If planted in the spring, EPHLA's germination coincides with that of many highly competitive summer weeds, and if not controlled, these weeds could readily overwhelm the young EPHLA planting. However, it is also true that planting EPHLA in the fall can lead to weed problems if its growth is slowed by cool temperatures at the same time that seasonal rains promote weed seed germination. While EPHLA would normally be grown as an annual crop, probably in rotation with other crops, it can at times regrow from the base after it is cut for harvest. If it could be managed in this way as a short-term perennial, it may be able to obtain an advantage over newly germinating weeds.

The objective of this study was to identify and evaluate herbicides that could prove useful in commercial cultivation of EPHLA.

Because EPHLA is a new introduction to North America, and thus a potential weed, herbicides that could control escapes of this plant were also noted.

\section{Materials and Methods}


69

70

7

74 The herbicides tested in this study were selected in one of four ways:

\section{1993).}

\subsection{Herbicide Selection} the Weed Science Society of America” (Ransom et al., 2010). an EPHLA crop (or for control of EPHLA escapes). potentially useful in EPHLA crop cultivation. EPHLA crop cultivation.

2.2 Locations and crop management common to all studies

To simplify future registration, all herbicides we tested were already registered in the USA for another crop at the time of these studies. Full chemical names of herbicides described herein can be found in "Common and Chemical Names of Herbicides Approved by

2) Known tolerance (or lack thereof) by weeds in the same genus or family was used to select possible candidates for weed control in

3) Some herbicides that were widely used to control common broadleaf weeds in the SW Oregon region were also considered as

4) Recommendations from chemical company scientists were used to select herbicides that may have selective weed control in 
85 The herbicide studies described in this paper were done at the Southern Oregon Research and Extension Center (SOREC) located

86

87 mixed, mesic, Pachic Haploxeroll).

88 content.

The general sequence of these experiments was to first test EPHLA tolerance to a wide range of PPI, PRE, or POST herbicides in greenhouse flats, followed by more detailed and more highly replicated field tests of the more likely herbicide candidates, which also included some lay-by herbicides (herbicides applied after crop emergence to prevent emergence of later-germinating weeds). Initial herbicide rates were chosen to be near the minimum that could be expected to provide an observable level of weed control, which ranged from the low to middle of rates registered for other crops. In some cases, rates suggested by chemical company scientists were used. Though some greenhouse studies were replicated to allow statistical analysis, they were not intended to be carried through seed harvest, but the later field experiments were continued through harvest to evaluate herbicide effects on EPHLA seed yield and seed oil

For the PPI treatments, the soil was sprayed and roto-tilled to a depth of about $75 \mathrm{~mm}$ in the field or mixed thoroughly in a rotating drum in the greenhouse before seeding. The PRE herbicides were sprayed after planting but before emergence. POST spray treatments were applied after EPHLA emergence to control emerged weeds. Lay-by treatments were applied following EPHLA emergence and after existing weeds had been controlled by cultivation to prevent later cycles of weed emergence. In each study described in this 
102 paper, herbicides were applied in water solutions, using compressed air at $260 \mathrm{kPa}$ pressure through a four-nozzle boom (Spraying

103

104

105

106

107

108

109

110

111

112

Systems TEEJET 8003 nozzles spaced $510 \mathrm{~mm}$ apart). The boom was mounted on a bicycle-wheel-frame sprayer and pushed by hand at $3.2 \mathrm{~km} \mathrm{hr}^{-1}$ to apply $390 \mathrm{~L} \mathrm{ha}^{-1}$.

Crop tolerance was rated relative to a hand-weeded treatment, with a rating of zero indicating no visible injury, and a 100 indicating crop death. Intermediate ratings were based on tissue necrosis, stunting, and vigor. The effectiveness of the herbicides against specific weed species is fairly well known, and thus was not separately rated. However, weed infestation observed in the un-weeded control plots was compared to the herbicide-treated plots to verify that apparent EPHLA herbicide tolerance, where EPHLA was not injured, was occurring in the presence of visible herbicide activity on weeds.

Irrigation was applied with standard droplet sprayer nozzles for the greenhouse studies and through hand-line impact sprinklers for the field studies. Irrigation was applied as needed to activate PRE herbicides and to keep enough available water in the root zone to allow vigorous vegetative growth. However, care was taken to avoid applying excess irrigation that could affect herbicide mobility, and thus its activity in the root zone. EPHLA is a drought-tolerant plant in its native habitat, so excess irrigation was avoided to minimize the chance of disease or other non-herbicidal factors inhibiting growth and vigor that would confound the results. Based on previous experience with EPHLA, irrigation was applied at about half the potential evapotranspiration rate $\left(\mathrm{PE}_{\mathrm{T}}\right)$, which resulted in soil 
moisture that generally remained within the $50 \%$ to $100 \%$ depletion range for plant available water. While this limited irrigation would cause moisture stress for many crop plants, EPHLA grows satisfactorily even under such low irrigation rates.

\subsection{Statistical analysis.}

Each replicated study was designed and analyzed as a randomized complete block. Data were subjected to analysis of variance using SAS statistical software (SAS, 2008). When a significant $(\mathrm{P}<0.05)$ treatment effect occurred, the least significant difference value was calculated to compare treatment means.

\subsection{PPI and PRE herbicides}

\subsubsection{Greenhouse tests.}

After preliminary screening tests in 1998, the first three replicated tests of PPI and PRE herbicides were conducted using greenhouse flats in 1999. Some herbicides were included in all three tests, with increasing rates in each successive test (resulting in a "low", “medium”, and "high” rate test of these herbicides). For each treatment, 100 EPHLA seeds were seeded by hand at about 6 mm depth in a $0.46 \mathrm{~m}$ by $0.91 \mathrm{~m}$ greenhouse flat, filled with field soil. This round of testing was meant to separate potentially useful herbicides from those that clearly inhibited EPHLA germination and emergence. Thus, each treatment was replicated only twice to allow statistical comparison only if large treatment differences occurred. PPI herbicides were sprayed and mixed into the soil just prior to 
seeding, whereas PRE herbicides were sprayed onto the surface soon after seeding with the boom sprayer. EPHLA tolerance to PPI and PRE herbicides was measured on several dates by counting the number of emerged EPHLA plants, but only the final emergence number for each rate test is reported herein.

\subsubsection{Field Test.}

Based on the greenhouse test results, several promising PPI and PRE herbicides were evaluated in the field in 2000. Each treatment plot was replicated four times. Individual plots were $13.7 \mathrm{~m}$ long, containing 4 rows spaced $0.51 \mathrm{~m}$ apart. EPHLA seed was seeded on 22 March using a Planet Jr. single row drill, set to place the seed at 6 to $12 \mathrm{~mm}$ depth, and about 80 seeds $\mathrm{m}^{-1}$ of row. PPI herbicides were roto-tilled into the soil the day before seeding, while PRE herbicides were applied through the boom sprayer the day after seeding.

Crop tolerance was measured by evaluating crop injury 3 and 7 weeks after treatment, and EPHLA was harvested at maturity in late August using a Hege 125C plot combine. Seed yield and 1000 seed weights were measured directly, and oil content was measured on cleaned samples using nuclear magnetic resonance techniques on an Oxford 4000 NMR Analyzer (Oxford Analytical Instruments, Ltd., Eynsham, Oxon, United Kingdom), using known EPHLA standard seed samples for calibration. Oil yield was calculated using seed yield and oil content values. 
153

154

155

\subsection{POST herbicides}

\subsubsection{Greenhouse tests.}

EPHLA has slow initial growth and a long vegetative phase, so it was expected that PPI and PRE herbicides would not typically provide enough control of weeds for the entire growing season. Because of the large number of potential POST herbicides, and the lack of published observations with EPHLA, two rounds of un-replicated screening tests were conducted in greenhouse flats to provide preliminary information before proceeding to more involved, replicated testing in the field. These preliminary POST tests were seeded in greenhouse flats and managed similar to the PPI/PRE tests, except sufficient seeds were planted to produce a dense stand of seedlings.

\subsubsection{Field Test 1.}

Based on the results from the greenhouse tests, promising POST herbicides were then tested in the field in 2005 and 2012 . In 2005 (Field Test 1), treatments were replicated twice. Individual plots were $9.1 \mathrm{~m}$ long, containing 4 rows spaced $0.61 \mathrm{~m}$ apart. EPHLA

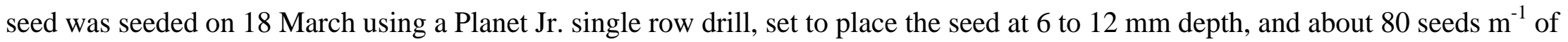
row. POST herbicides were sprayed over the crop on 9 June, when the EPHLA plants were between 150 and 250 mm tall, using the boom sprayer. Weeds were removed by hand from the control treatments and plots receiving DCPA, which is normally used as a lay- 
by herbicide. Crop tolerance was measured 2 and 4 weeks following herbicide application. In addition, effects of herbicides on crop maturity and seed shattering were measured on 16 August, approximately one week before harvest. This was done by randomly selecting several individual branches from each plot, counting the number of individual seed pods on each branch, and designating them as either green, brown, or shattered.

At maturity, plots were harvested on 24 August using a Hege 125C research plot combine. In some plots a significant number of immature or partially mature seeds appeared to remain on the plants after combining. Thus, crop residue was left in the field for two weeks to completely dry and then was combined again. Seed yield, 1000 seed weight, oil content, and oil yield were measured or calculated for both combine runs. EPHLA sometimes can regrow during the fall and winter after harvest, so managing EPHLA as a perennial was considered. To determine how herbicide use might affect this approach, post-harvest regrowth was rated on 28 September, five weeks after combine harvest.

\subsubsection{Field Test 2.}

The field study of POST herbicides was repeated in 2012, although two herbicides that caused significant EPHLA damage with minimal seed yield in Field Test 1 were not included in Field Test 2. Treatments were replicated four times in Field Test 2. Individual plots were $6.1 \mathrm{~m}$ long, containing 4 rows spaced $0.51 \mathrm{~m}$ apart. EPHLA seed was seeded on 6 April using a Planet Jr. single row drill, set to place the seed at 6 to $12 \mathrm{~mm}$ depth, and about 80 seeds $\mathrm{m}^{-1}$ of row. POST herbicides were sprayed over the crop on 14 June, 
when the EPHLA plants were about $300 \mathrm{~mm}$ tall, using the boom sprayer. Weeds were removed by hand from the control treatments and plots receiving DCPA, which is normally used as a lay-by herbicide. Crop tolerance was measured 9 and 36 days after herbicide application. In addition, effects of herbicides on crop maturity and seed shattering were measured on 30 August, approximately one week before harvest. This was done in the same way as the previous field POST herbicide study, by randomly selecting several individual branches from each plot, counting the number of individual seed pods on each branch, and designating them as either green, brown, or shattered.

At maturity, plots were harvested on 5 September using a Hege 125C plot combine. Essentially all the seed threshed out well during the first combine run so that a second combine operation was not necessary. Seed yield, 1000 seed weight, oil content, and oil yield were measured or calculated. Unlike the previous field study, there was little fall regrowth from any of the plots in this study.

\section{Results and Discussion}

\subsection{PPI and PRE herbicides}

$\underline{3.1 .1}$ Greenhouse tests. 
In almost every case, herbicides either severely reduced EPHLA emergence (diuron and EPTC) at all herbicide rates tested, or had little effect on emergence at any of the tested rates (Table 1). Due to EPHLA's obvious lack of tolerance to diuron and EPTC at the low and moderate rates, they were not included in the high rate test, and were dropped from further consideration. EPHLA emergence was not hindered by chloridazon at the low and moderate rates compared to the control, but it was not evaluated at a higher rate. Compared with some of the herbicides tested, chloridazon caused some visible injury, but not enough to disqualify it from further consideration. In contrast, chloridazon did not injure EPHLA in the earlier test in Spain, while providing good weed control and good seed yield (Vogel et al., 1993). EPHLA emergence was not hindered by any of the dinitroaniline herbicides (trifluralin, pendimethalin, ethalfluralin, or benefin) when compared to the control treatment or to each other. Pendimethalin was not included in the first two tests, but was tested at three rates both PPI and PRE in the third experiment, where EPHLA emergence was similar to the control treatment for all six cases.

\section{Thus the initial greenhouse flat tests of EPHLA emergence when treated with PPI and PRE herbicides suggested that benefin,} ethalfluralin, trifluralin, and pendimethalin were excellent candidates for continued testing, while chloridazon and DCPA had good potential. 
The most promising PPI and PRE herbicides from the greenhouse experiments were evaluated in the field at multiple rates. Overall, the EPHLA crop tolerance was good, as visible injury observed both three and seven weeks after seeding was very low for all herbicides and rates tested (Table 2). Pendimethalin tended to cause more injury than the other herbicides, but even its response was considered acceptable. EPHLA injury from pendimethalin applied both PRE and PPI was significantly greater at the high rate than the low rate measured 7 weeks after seeding, and this difference was more pronounced than it had been after 3 weeks. Pendimethalin applied PPI tended to cause somewhat greater injury to EPHLA than the same rate applied PRE, but the difference only significant for the low rate 3 weeks after seeding.

Compared to other crop management trials of EPHLA we have done over the years, seed yields in this test were excellent for all treatments and no significant differences were observed, although a trend for decrease in yield was observed for EPHLA treated with pendimethalin PRE. Likewise, seed oil contents were very good for all treatments, with no significant differences between treatments, but there was a tendency for a slight decrease in oil content for the pendimethalin treatments compared to all others. Oil yield is a function of both seed yield and seed oil content, so it was not surprising that oil yield was similar for all treatments, although EPHLA treated with pendimethalin PRE tended to have a slightly lower oil yield than the other treatments.

The 1000 seed weights for three of the four pendimethalin treatments were significantly lower than five of the six benefin, ethalfluralin, and trifluralin treatments. In all cases the 1000 seed weight was similar to or greater than typically observed values for 
indehiscent mutants, which tend to be larger than seeds from dehiscent wild types (Pascual-Villalobos et al., 1993). This indicates that very healthy, mature seeds were produced in this experiment. The results for trifluralin also confirmed previous testing in Spain, where trifluralin did not injure the crop (Vogel et al., 1993).

\subsection{POST Herbicides}

\subsubsection{Greenhouse Tests.}

Damage to EPHLA by the POST herbicides in the two rounds of un-replicated screening tests in the greenhouse varied greatly, resulting in a group of potentially useful herbicides that were carried forward for more detailed field testing.

\subsubsection{Field Test 1.}

The two field experiments more completely compared the effects of various POST herbicides on EPHLA growth and seed production than the greenhouse tests did. In these two field studies, seed yields were in the $200-300 \mathrm{~kg} \mathrm{ha}^{-1}$ range, more similar to yields observed in other crop management studies we have conducted over the years. In the first field study, 20 POST herbicide treatments (including two rates of some herbicides) were evaluated for their effects on crop growth and injury, seed yield and size, seed oil content, and oil yield (Table 3). 
Crop injury was significant and unacceptable for bromoxynil, 2,4-D, and picloram. Visible injury from oxyfluorfen was not as severe, but still was more than desirable for routine crop production. At 14 and 29 days after treatment, EPHLA appeared to tolerate the other herbicides well, as there was little or no visible crop injury.

EPHLA treated with dicamba exhibited the greatest delay in maturity, displaying many green pods with relatively few shattered or brown pods. EPHLA treated with imazethapyr, alachlor at the high rate, and DCPA also had relatively more green pods and fewer shattered pods, but they also had an appreciable number of brown pods. Herbicide treatments that resulted in a relatively high proportion of brown pods with few shattered pods included clopyralid, bentazon, imazapyr at the low rate, imazamox, and ethofumesate. If all else is equal, a crop with a high percentage of brown, mature seed pods and few shattered pods is most desirable.

EPHLA began to regrow after harvest in some plots, despite the lack of irrigation and minimal rain. The potential to manage this crop as a short-term perennial would improve management options, so plants were allowed to regrow for one month after harvest to measure this effect. EPHLA had no regrowth in the 2,4-D treatments, but regrowth was slow and/or sporadic for several other herbicides. EPHLA that had consistently good regrowth, suggesting seed production may be possible the following year, included plants treated with metsulfuron, imazapyr (low rate), ethofumesate, and dicamba. 
Not too surprisingly, in many cases there was a strong connection between visible herbicide injury and eventual seed yield, oil content, and oil yield. Thus, where injury was minimal, seed yield and related parameters were usually very good to excellent, i.e., for the clopyralid, alachlor, acifluorfen, and chloridazon treatments. Conversely, where herbicide injury was severe, seed production and quality were usually also adversely affected, i.e., 2,4-D and picloram. In an intermediate situation, EPHLA treated with bentazon and DCPA exhibited a fairly low injury, but also produced a somewhat decreased seed yield.

However, the connection between visible injury and eventual seed yield was not always obvious. Oxyfluorfen and bromoxynil caused a moderate to high degree of injury, but EPHLA produced a fairly good to excellent yield and seed quality (especially for the lower rate of each herbicide). In these cases, EPHLA was apparently able to recover from the initial herbicide injury and, in a presumably less competitive environment, created enough new leaf area and seed pods to produce fairly good to very good yields by harvest.

In contrast, several herbicides, including metsulfuron, imazapyr, imazethapyr, imazamox, ethofumesate, and dicamba, caused moderately low to very low visible injury, but EPHLA produced very low seed yield and/or seed oil content. Thus, these herbicides were not overly phytotoxic to the plant, but clearly interfered with some portion of its reproductive cycle, resulting in a stand of reasonably healthy-looking plants that produced very few seed pods. 
Because some plots appeared to have a large number of un-threshed seed pods after the first combine operation, threshed material was allowed to dry in the field for two weeks before a second threshing with the plot combine, as described above. Although seed yield, seed oil content, and 1000 seed weights were measured on seeds harvested in this second combine operation, the values were very low and did not contribute much to the total seed and oil yield (data not shown). Thus, only total seed yield and oil yield values are shown in Table 3. The seed oil content and 1000 seed weight values in Table 3 refer only to the mature seed harvested during the first combine operation.

\subsubsection{Field Test 2.}

In the second field study of POST herbicides, 18 treatments (including two rates of some herbicides) were evaluated for their effects on crop growth and injury, seed yield and size, seed oil content, and oil yield (Table 4).

Similar to the first field test, visible crop injury was significant for bromoxynil, especially at the higher rate. Initial injury from oxyfluorfen was also significant, but plants improved dramatically by the second evaluation date. There was somewhat more damage from acifluorfen than in the first field study, but symptoms improved with time for this treatment as well. Damage from ethofumesate and dicamba was low initially, but appeared to worsen by the second evaluation date. At both 9 and 36 days after treatment, EPHLA appeared to tolerate the other herbicides very well, as there was little or no visible crop injury. 
302 Similar to the first field test, EPHLA treated with dicamba exhibited the greatest delay in maturity, displaying many green pods with 303 relatively few shattered or brown pods. Also similar to the first field test, EPHLA treated with imazethapyr, alachlor at the high rate, and DCPA also had relatively more green pods and fewer shattered pods, but they also had an appreciable number of brown pods. Herbicide treatments that resulted in a relatively high proportion of brown pods with few shattered pods included clopyralid, bentazon, imazapyr, imazamox, and ethofumesate. These responses were similar to those in the first field study. If all else is equal, a crop with a high percentage of brown, mature seed pods and few shattered pods is most desirable. Unlike the first field test, there was very little EPHLA regrowth after harvest. Utilizing potential regrowth as a management option for subsequent year's seed production requires further study to understand what conditions encourage this crop behavior. Also unlike the first field test, the seed pods threshed well the first time for all herbicide treatments in the second field test, avoiding the need for an extended drying period and second combine operation.

As in the first field study, there was often a strong connection between visible herbicide injury and eventual seed yield, oil content, and oil yield. Thus, where injury was minimal, seed yield and related parameters were usually very good to excellent, i.e., for the clopyralid, alachlor, and chloridazon treatments. Conversely, where herbicide injury was severe, seed production and quality were usually also adversely affected, i.e., the high rate of bromoxynil. In an intermediate situation, EPHLA treated with bentazon and DCPA exhibited little or no visible injury, but also produced an intermediate seed yield, similar to results in the first field test. 
As in the first field test, oxyfluorfen caused a moderate to high degree of injury (especially on the first injury rating date), but EPHLA produced a fairly good to excellent yield and seed quality. The response to acifluorfen was similar to that of oxyfluorfen in this second field test, with moderate initial injury improving over time and a moderately good final seed yield. In these cases, EPHLA was apparently able to recover from the initial herbicide injury and, in a presumably less competitive environment, created enough new leaf area and seed pods to produce fairly good to very good yields by harvest. In contrast, injury from dicamba and ethofumesate seemed to get worse over time, and this effect was more pronounced in the second field test than it had been in the first. However, both herbicides resulted in low seed yields in both tests. Similar to the first field test, the response to bromoxynil was more of a doseresponse relationship, with the higher rate causing more visible injury and eventual lower yield.

Similar to the results from the first field test, several herbicides, including metsulfuron, imazapyr, imazethapyr, and imazamox caused low visible injury, but EPHLA produced very low seed yield and/or seed oil content. Thus, these herbicides were not overly phytotoxic to the plant, but clearly interfered with some portion of its reproductive cycle, which resulted in a stand of reasonably healthy-looking plants that produced very few seed pods.

There were significant differences in 1000 seed weight which generally followed the pattern observed in the first field study. Seed weights were highest for the alachlor treatment, and lowest for imazapyr. Unlike the first field test, seed weights were also 
significantly lower than the other treatments for metsulfuron and dicamba. As discussed above for seed yield, imazapyr and metsulfuron clearly interfered with the crop’s reproductive cycle.

In earlier studies in Spain, neither chloridazon nor bentazon caused visible injury to EPHLA, and seed yield was good for both treatments (Vogel et al., 1993). In our second field test, seed yield following bentazon treatment was significantly lower than the untreated control, and tended to be lower than the chloridazon treatment, a similar pattern to that observed in the first field test (Tables 3 and 4). Unlike the first field test, seed oil content was essentially identical for these three treatments. The results from these two field studies might suggest that bentazon is slightly more injurious than was evident from the study in Spain, but probably not enough to exclude bentazon from future consideration without additional data to confirm these trends.

\subsection{New Crop weed control implications}

Introduction of a new crop species, especially one that is as hardy and drought tolerant as EPHLA, creates the potential for the plant to escape as a weed. Several PPI, PRE, and POST herbicides evaluated in this study were quite toxic to EPHLA, and apparently would be good candidates for controlling any unwanted escapes from cultivation. Other herbicides not evaluated in these studies may also be useful in controlling potential EPHLA escapes. Several weeds common in the western USA are in the Euphorbiaceae family, and 
several herbicides are registered to control such weeds in certain cropping circumstances. If EPHLA is grown commercially, future researchers may wish to evaluate these compounds as control agents for EPHLA to limit the potential risk of EPHLA escaping as a weed.

\section{Conclusions}

Euphorbia lagascae has good potential to become an important crop source of epoxy fatty acids in semi-arid regions. Crop yield is enhanced with good weed control, and EPHLA exhibited good tolerance and seed yield when treated with some of the herbicides we tested. The most promising PPI and PRE herbicides included benefin, ethalfluralin, and trifluralin. Pendimethalin also gave acceptable results but with slightly lower seed oil content and 1000 seed weight. The most promising POST herbicides included clopyralid, alachlor, acifluorfen, and chloridazon, to which EPHLA exhibited very good crop tolerance and produced very good to excellent yields. Oxyfluorfen initially caused significant vegetative injury, but EPHLA produced good to excellent yields, suggesting that the damaging effect on EPHLA was temporary and did not affect the reproductive processes. Injury and seed yield both seemed ratedependent for the bromoxynil treatments, such that higher rates caused more injury and lower yield, although both were acceptable in certain cases. Bentazon and DCPA caused a low level of visible injury, but EPHLA treated with them produced a somewhat decreased seed yield, indicating that these herbicides could be useful if the effects of rate and timing were better understood. Metsulfuron, imazapyr, imazethapyr, imazamox, ethofumesate, and dicamba did not cause much vegetative injury (although injury 
from dicamba and ethofumesate generally increased over time), but they all adversely affected EPHLA seed production in some way, resulting in very low yields even in the absence of obvious visible injury. Several of the PPI, PRE, and POST herbicides were highly toxic to EPHLA, and would be useful to help avoid a weed problem by killing escaped EPHLA plants.

\section{Acknowledgements}

Portions of this research were funded by a USDA Special Grant, Agreement \# 94-COOP-2-1243.

This research was also supported by state and federal formula funds appropriated to Oregon State University and the Oregon Agricultural Experiment Station.

The author thanks Dr. Steven Knapp, Oregon State University, for use of his NMR equipment for seed oil analysis, to Mr. Bliss Phillips, USDA-ARS-NCAUR, Peoria, IL, for developing the EPHLA seed oil standards used in the NMR analysis, and to Dr. Terry Isbell, USDA-ARS-NCAUR, Peoria, IL, for seed oil analysis on their NMR machine.

\section{References}


Brownback, S., Glaser, L., 1992. Agriculture provides U.S. industry with diverse raw materials. In: New crops, new uses, new markets: 1992 Yearbook of Agriculture, pp. 2-9. U.S. Department of Agriculture, U.S. Govt. Printing Office, Washington, D.C., USA.

Carlson, K.D., Schneider, W.J., Chang, S.P., Princen, L.H., 1981. Vernonia galamensis seed oil: A new source for epoxy coatings.

American Oil Chemists Society Monograph 9, 297-318.

Carlson, K.D., Chang, S.P., 1985. Chemical epoxidation of a natural unsaturated epoxy seed oil from Vernonia galamensis and a look at epoxy oil markets. Journal of the American Oil Chemists Society 62, 934-939.

Dierig, D.A., Thompson, A.E., 1993. Vernonia and Lesquerella potential for commercialization. In: New Crops (eds J. Janick and J.E. Simon), pp. 362-371. Wiley, New York, USA.

Earle, F.R., 1970. Epoxy oils from plant seeds. Journal of the American Oil Chemists Society 47, 510-513.

Kleiman, R., 1990. Chemistry of new industrial oilseed crops. In: Advances in New Crops (eds J. Janick and J.E. Simon), pp. 196-203. Timber Press, Portland, Oregon, USA. 
401 Kleiman, R., Smith, C.R., Yates, S.G., 1965. Search for new industrial oils. XII. Fifty-eight Euphorbiaceae oils, including one rich in

402 vernolic acid. Journal of the American Oil Chemists Society 42, 169-172.

403

404

405

406

407

408

409

410

411

412

413

414

Pascual-Villalobos, M.J., Ortiz, J.M., Correal, E., 1993. Morphometric characterization of seeds of Euphorbia lagascae. Seed Science \& Technology 21, 53-60.

Pascual-Villalobos, M.J., Robbelen, G., Correal, E., 1994. Production and evaluation of indehiscent mutant genotypes in Euphorbia lagascae. Industrial Crops and Products 3, 129-143.

Ransom, C.V., Grey, T., Johnson, E., Keese, R.J., Riechers, D.E., Senseman, S.A., Miller, T.W.,

Tardif, F., 2010. Common and Chemical Names of Herbicides Approved by the Weed Science Society of America. Weed Science 58, 511-518.

Roseberg, R.J., 1996. Underexploited temperate industrial and fiber crops. In: Progress in New Crops (ed J. Janick), pp. 60-84. ASHS Press, Alexandria, Virginia, USA.

Roseberg, R.J., Shuck, R.A., 2009. Agronomic Requirements of Euphorbia lagascae: A 
421

426

427
Potential New Drought-Tolerant Crop for Semi-Arid Oregon: 2009 Results. Klamath Basin Research \& Extension Center Annual Research Report.

http://oregonstate.edu/dept/kbrec/research-klamath-basin-2009-annual-report.

SAS Institute, 2008. The SAS System for Windows, Version 9.2. SAS Institute Inc., Cary, NC, USA.

Trumbo, D.L., 1998. Epoxy oil from vernonia for paints and coatings. In: Association for the Advancement of Industrial Crops Annual Meeting Abstracts, Phoenix, Arizona, p. 18.

Turley, D., Froment, M., Cook, S. (eds), 2000. Development of Euphorbia lagascae as a new industrial oil crop. European Community Concerted Action (FAIR-CT98/4460) Handbook. ADAS Woodthorne, Wolverhampton, United Kingdom.

Vogel, R., Pascual-Villalobos, M.J., Robbelen, G., 1993. Seed oils for new chemical applications. 1. Vernolic acid produced by Euphorbia lagascae. Agnew Botany 67, 31-41. 
438

439

440

441

442

443

444

445

446

447

448

449

450

Table 1. EPHLA tolerance measured as percent emergence after treatment with herbicides at low, medium, and high rates applied preplant incorporated (PPI) and preemergence (PRE). 100 seeds planted for each greenhouse flat.

\begin{tabular}{|c|c|c|c|c|}
\hline Herbicide & Timing & $\begin{array}{l}\text { Rate } \\
\text { (kg ha }^{-1}\end{array}$ & a.i.) & Emergence $^{1}$ \\
\hline \multicolumn{5}{|l|}{ Low rate test } \\
\hline Benefin & PPI & 1.12 & & 76.0 \\
\hline Chloridazon & PRE & 2.80 & & 71.5 \\
\hline DCPA & PPI & 6.72 & & 79.5 \\
\hline DCPA & PRE & 6.72 & & 58.0 \\
\hline Diuron & PRE & 1.68 & & 20.5 \\
\hline EPTC & PPI & 3.36 & & 24.5 \\
\hline Ethalfluralin & PPI & 0.56 & & 86.0 \\
\hline Trifluralin & PPI & 1.12 & & 87.5 \\
\hline Control & & na & & 78.5 \\
\hline Mean & & -- & & 64.7 \\
\hline Prob. $>$ F & & -- & & $<0.001$ \\
\hline LSD (0.05) & & -- & & 18.4 \\
\hline C.V. (\%) & & -- & & 12.3 \\
\hline \multicolumn{5}{|c|}{ Medium rate test } \\
\hline Benefin & PPI & 2.24 & 72.0 & \\
\hline Chloridazon & PRE & 5.60 & 55.5 & \\
\hline DCPA & PPI & 13.44 & 48.0 & \\
\hline Diuron & PRE & 3.36 & 26.0 & \\
\hline EPTC & PPI & 6.72 & 0 & \\
\hline Ethalfluralin & PPI & 1.12 & 58.5 & \\
\hline Trifluralin & PPI & 2.24 & 67.5 & \\
\hline Control & & na & 55.0 & \\
\hline Mean & -- & -- & 44.8 & \\
\hline Prob. $>$ F & -- & & 0.003 & \\
\hline
\end{tabular}




$\begin{array}{lllll}473 & \text { LSD (0.05) } & -- & & 24.4 \\ 474 & \text { C.V. (\%) } & -- & & 23.0 \\ 475 & & & & \\ 476 & \text { High rate test } & & & \\ 477 & & & & \\ 478 & \text { Benefin } & \text { PPI } & 4.48 & 64.5 \\ 479 & \text { DCPA } & \text { PPI } & 26.90 & 70.0 \\ 480 & \text { DCPA } & \text { PRE } & 26.90 & 75.5 \\ 481 & \text { Ethalfluralin } & \text { PPI } & 2.24 & 73.5 \\ 482 & \text { Trifluralin } & \text { PPI } & 4.48 & 64.0 \\ 483 & \text { Pendimethalin } & \text { PPI } & 1.12 & 74.5 \\ 484 & \text { Pendimethalin } & \text { PPI } & 2.24 & 79.0 \\ 485 & \text { Pendimethalin } & \text { PPI } & 4.48 & 80.5 \\ 486 & \text { Pendimethalin } & \text { PRE } & 1.12 & 79.5 \\ 487 & \text { Pendimethalin } & \text { PRE } & 2.24 & 75.0 \\ 488 & \text { Pendimethalin } & \text { PRE } & 4.48 & 79.0 \\ 489 & \text { Control } & & \text { na } & 74.0 \\ 490 & & & & \\ 491 & \text { Mean } & --- & & 73.2 \\ 492 & \text { Prob. > F } & --- & & 0.132 \\ 493 & \text { LSD (0.05) } & --- & & \text { NSD } \\ 494 & \text { C.V. (\%) } & --- & & 10.2\end{array}$

495 (1)

496

497

1 Emergence measured 34 days after planting (DAP) for low rates, 29 DAP for medium rates, and 28 DAP for high rate test. 
501

502

503

504

505

506
507

507

508
509

510

511

512

513

514

515

516

517

518

519

520

521

522
523

524

525

526

527

528

529

530

531

533
Table 2. EPHLA injury, seed yield, oil content, and seed weight following treatment with preplant incorporated (PPI) and pre-emergence (PRE) herbicides in the field.

\begin{tabular}{|c|c|c|c|c|c|c|c|c|}
\hline Herbicide & Timing & $\begin{array}{l}\text { Rate } \\
\text { (kg ha }{ }^{-1} \\
\text { a.i.) }\end{array}$ & $\begin{array}{l}\text { Injury@ } \\
3 \text { wk (\%) }\end{array}$ & $\begin{array}{l}\text { Injury @ } \\
7 \text { wk (\%) }\end{array}$ & $\begin{array}{l}\text { Seed } \\
\text { Yield } \\
\left(\mathrm{kg} \mathrm{ha}^{-1}\right)\end{array}$ & $\begin{array}{l}\text { Seed oil } \\
\text { content } \\
(\%)\end{array}$ & $\begin{array}{l}\text { ield } \\
\left.a^{-1}\right)\end{array}$ & $\begin{array}{l}1000 \text { Seed } \\
\text { Weight } \\
\text { (g) }\end{array}$ \\
\hline Benefin & PPI & 1.12 & 1 & 0 & 1000 & 50.4 & 505 & 12.05 \\
\hline Benefin & PPI & 2.24 & 1 & 0 & 1090 & 50.9 & 555 & 12.08 \\
\hline Ethalfluralin & PPI & 1.12 & 2 & 0 & 1070 & 50.9 & 543 & 12.02 \\
\hline Ethalfluralin & PPI & 2.24 & 5 & 2 & 1040 & 50.5 & 523 & 12.02 \\
\hline Trifluralin & PPI & 1.12 & 2 & 0 & 1210 & 50.5 & 613 & 11.92 \\
\hline Trifluralin & PPI & 2.24 & 5 & 8 & 1060 & 50.0 & 531 & 12.35 \\
\hline Pendimethalin & PPI & 1.12 & 15 & 2 & 1040 & 49.3 & 512 & 11.26 \\
\hline Pendimethalin & PPI & 2.24 & 18 & 10 & 1040 & 49.5 & 514 & 11.93 \\
\hline Pendimethalin & PRE & 1.12 & 8 & 0 & 925 & 50.3 & 467 & 11.34 \\
\hline Pendimethalin & PRE & 2.24 & 15 & 8 & 922 & 48.7 & 450 & 11.49 \\
\hline Control & & & 0 & 0 & 1080 & 50.5 & 545 & 12.05 \\
\hline Mean & & -- & 7 & 3 & 1040 & 50.1 & 522 & 11.85 \\
\hline Prob. > F & & -- & $<0.001$ & 0.002 & 0.423 & 0.254 & 0.328 & 0.008 \\
\hline LSD (0.05) & & -- & 6 & 4 & NSD & NSD & NSD & 0.48 \\
\hline C.V. (\%) & & -- & 39.8 & 60.8 & 10.6 & 1.6 & 10.6 & 1.8 \\
\hline
\end{tabular}


535

537

538

539

540

541

542 .
Table 3. Injury rating, evaluation of pod maturity, seed yield, seed oil content, oil yield, 1000 seed weight and post-harvest regrowth rating as affected by POST herbicide treatments (Field Test 1).

\begin{tabular}{|c|c|c|c|c|c|c|c|c|c|c|c|}
\hline Herbicide & $\begin{array}{l}\text { Rate } \\
\text { (kg } \\
\text { ha }^{-1} \\
\text { a.i.) }\end{array}$ & $\begin{array}{l}\text { Injury } \\
@ \\
14 \text { days } \\
(\%)\end{array}$ & $\begin{array}{l}\text { Injury } \\
@ \\
29 \text { days } \\
(\%)\end{array}$ & $\begin{array}{l}\text { Shattered } \\
\text { Pods (\%) }\end{array}$ & $\begin{array}{l}\text { Brown } \\
\text { Pods } \\
(\%)\end{array}$ & $\begin{array}{l}\text { Green } \\
\text { Pods } \\
(\%)\end{array}$ & $\begin{array}{l}\text { Total } \\
\text { Seed } \\
\text { Yield } \\
\left(\mathrm{kg} \mathrm{ha}^{-1}\right)\end{array}$ & $\begin{array}{l}\text { Seed Oil } \\
\text { Content } \\
(\%) \\
\left(1^{\mathrm{st}} \text { run }\right)\end{array}$ & $\begin{array}{l}\text { Total } \\
\text { Oil } \\
\text { Yield }{ }^{1} \\
\text { (kg ha }^{-1} \\
\text { ) }\end{array}$ & $\begin{array}{l}1000 \text { Seed } \\
\text { Weight (g) } \\
\left(1^{\text {st }} \text { run }\right)\end{array}$ & $\begin{array}{l}\text { Post- } \\
\text { harvest } \\
\text { Regrowth }^{2} \\
\text { Rating }^{2}\end{array}$ \\
\hline Clopyralid & 0.28 & 0 & 8 & 8.7 & 82.0 & 9.2 & 266 & 50.6 & 130 & 12.40 & 1.0 \\
\hline Oxyfluorfen & 0.28 & 30 & 30 & 18.8 & 66.2 & 15.0 & 246 & 49.8 & 119 & 13.14 & 1.0 \\
\hline Oxyfluorfen & 0.56 & 50 & 38 & 9.3 & 52.1 & 38.6 & 164 & 48.4 & 77 & 12.11 & 1.0 \\
\hline Bentazon & 1.68 & 4 & 10 & 14.0 & 70.0 & 16.0 & 172 & 50.4 & 84 & 13.04 & 1.0 \\
\hline Alachlor & 2.24 & 5 & 0 & 12.8 & 69.7 & 17.5 & 294 & 49.1 & 139 & 13.43 & 1.5 \\
\hline Alachlor & 4.48 & 20 & 0 & 9.5 & 46.4 & 44.1 & 268 & 49.1 & 126 & 14.19 & 1.0 \\
\hline Metsulfuron & 0.007 & 15 & 8 & 27.9 & 63.9 & 8.2 & 26 & 41.8 & 9 & 11.21 & 4.0 \\
\hline Acifluorfen & 0.28 & 2 & 2 & 28.4 & 45.5 & 26.0 & 221 & 48.7 & 104 & 13.69 & 1.0 \\
\hline Imazapyr & 0.14 & 10 & 2 & 16.2 & 75.5 & 8.3 & 20 & 45.9 & 8 & 12.57 & 4.5 \\
\hline Imazapyr & 0.28 & 10 & 0 & 44.0 & 55.9 & 0.0 & 18 & 46.8 & 8 & 10.45 & 3.0 \\
\hline Imazethapyr & 0.07 & 8 & 0 & 2.9 & 45.1 & 52.0 & 78 & 47.8 & 34 & 12.94 & 3.0 \\
\hline Imazamox & 0.07 & 10 & 0 & 12.4 & 74.2 & 13.4 & 62 & 47.9 & 28 & 13.54 & 3.0 \\
\hline Ethofumesate & 2.24 & 5 & 10 & 16.8 & 67.9 & 15.2 & 50 & 43.9 & 20 & 11.90 & 4.5 \\
\hline DCPA & 6.72 & 5 & 0 & 2.9 & 54.9 & 42.2 & 141 & 45.8 & 61 & 13.30 & 1.5 \\
\hline Dicamba & 0.56 & 18 & 15 & 15.6 & 12.7 & 71.7 & 33 & 43.8 & 13 & 11.20 & 4.0 \\
\hline Bromoxynil & 0.28 & 60 & 70 & 51.6 & 13.8 & 34.6 & 125 & 48.6 & 59 & 13.51 & 1.5 \\
\hline Bromoxynil & 0.56 & 75 & 92 & 20.5 & 66.1 & 13.4 & 65 & 48.0 & 31 & 15.38 & 1.0 \\
\hline $2,4-\mathrm{D}$ & 1.12 & 80 & 90 & $*^{3}$ & $*^{3}$ & $* 3$ & 38 & 49.8 & 19 & 12.24 & 0.0 \\
\hline Chloridazon & 3.92 & 0 & 5 & 25.5 & 51.2 & 23.3 & 239 & 49.8 & 116 & 13.31 & 0.5 \\
\hline Picloram & 0.56 & 35 & 55 & 36.1 & 26.7 & 37.3 & 39 & 49.3 & 17 & 14.53 & 1.5 \\
\hline Control & na & 0 & 0 & 24.9 & 70.9 & 4.2 & 261 & 50.4 & 131 & 11.52 & 3.0 \\
\hline Mean & -- & 22 & 22 & 19.9 & 55.5 & 24.5 & 135 & 47.9 & 64 & 12.82 & 2.0 \\
\hline Prob. $>$ F & & 0.001 & 0.001 & 0.070 & 0.004 & 0.001 & 0.001 & 0.007 & 0.001 & 0.112 & 0.001 \\
\hline LSD (0.05) & -- & 8 & 7 & NSD & 34.9 & 25.4 & 110 & 4.0 & 55 & NSD & 1.6 \\
\hline C.V. (\%) & & 16.5 & 15.7 & 99.9 & 44.4 & 73.1 & 39.1 & 4.0 & 41.4 & 10.1 & 37.6 \\
\hline
\end{tabular}


1 Total oil yield calculated as (first run seed yield times first run oil content) plus (second run seed yield times second run oil content). Separate data for first and second runs not shown.

${ }^{2}$ Evaluation of post-harvest regrowth was done using a rating scale that ranged from 0 for very brown, dead plants to 5 for plants showing very green, vigorous regrowth of 200 to $400 \mathrm{~mm}$ tall.

*3 Plants within in the plot areas randomly sampled for pod maturity analysis in the 2,4-D treatment had only dead plants, thus no pod maturity readings were recorded for that treatment. 
555

Table 4. Injury rating, evaluation of pod maturity, seed yield, seed oil content, oil yield, and 1000 seed weight as affected by POST herbicide treatments (Field Test 2).

Herbicide

Clopyralid
Oxyfluorfen
Oxyfluorfen
Bentazon
Bentazon
Alachlor
Metsulfuron
Acifluoren
Acifluorfen
Imazapyr
Imazethapyr
Imazamox
Ethofumesate
DCPA
Dicamba
Bromoxynil
Bromoxynil
Chloridazon
Control
Mean
Prob. > F
LSD (0.05)
CV \%

\begin{tabular}{|c|c|c|c|}
\hline $\begin{array}{l}\text { Rate } \\
\text { (kg } \\
\text { ha }^{-1} \text { a.i.) }\end{array}$ & $\begin{array}{l}\text { Injury } \\
\text { @ } 9 \\
\text { days } \\
(\%)\end{array}$ & $\begin{array}{l}\text { Injury } \\
@ 36 \\
\text { days } \\
(\%)\end{array}$ & $\begin{array}{l}\text { Shattere } \\
\text { Pods (\% }\end{array}$ \\
\hline 0.28 & 1 & 4 & 11.5 \\
\hline 0.28 & 38 & 11 & 19.5 \\
\hline 0.56 & 52 & 11 & 12.0 \\
\hline 1.12 & 4 & 6 & 15.8 \\
\hline 2.24 & 5 & 5 & 18.2 \\
\hline 4.48 & 15 & 8 & 12.0 \\
\hline 0.007 & 8 & 9 & 28.2 \\
\hline 0.28 & 18 & 9 & 30.2 \\
\hline 0.56 & 29 & 15 & 21.8 \\
\hline 0.14 & 6 & 10 & 19.0 \\
\hline 0.07 & 5 & 5 & 6.0 \\
\hline 0.07 & 5 & 8 & 15.8 \\
\hline 2.24 & 5 & 20 & 17.2 \\
\hline 6.72 & 0 & 0 & 5.2 \\
\hline 0.56 & 10 & 26 & 18.2 \\
\hline 0.28 & 21 & 12 & 52.8 \\
\hline 0.56 & 50 & 41 & 26.8 \\
\hline 3.92 & 1 & 0 & 27.8 \\
\hline na & 0 & 0 & 27.8 \\
\hline - & 14 & 10 & 20.3 \\
\hline -- & $<0.001$ & $<0.001$ & $<0.001$ \\
\hline -- & 6 & 9 & 11.8 \\
\hline -- & 29.0 & 58.0 & 41.1 \\
\hline
\end{tabular}

$\begin{array}{ll}\text { Brown } & \text { Green } \\ \text { Pods (\%) } & \text { Pods (\%) } \\ & \\ & \\ & \\ 81.5 & 7.0 \\ 66.0 & 14.5 \\ 55.2 & 32.8 \\ 72.5 & 11.8 \\ 70.5 & 11.2 \\ 44.8 & 43.2 \\ 65.0 & 6.8 \\ 47.0 & 22.8 \\ 48.0 & 30.2 \\ 79.0 & 2.0 \\ 48.2 & 45.8 \\ 73.8 & 10.5 \\ 70.0 & 12.8 \\ 55.0 & 39.8 \\ 16.8 & 65.0 \\ 18.8 & 28.5 \\ 56.2 & 17.0 \\ 50.2 & 22.0 \\ 68.8 & 3.5 \\ 57.2 & \\ <0.001 & 22.5 \\ 13.2 & <0.001 \\ 16.2 & 11.0 \\ & 34.7\end{array}$

$\begin{array}{ll}\begin{array}{l}\text { Seed } \\ \text { Yield } \\ \left(\mathrm{kg} \mathrm{ha}^{-1}\right)\end{array} & \begin{array}{l}\text { Seed Oil } \\ \text { Content }(\%)\end{array} \\ & \\ & \\ 232 & 44.1 \\ 224 & 44.1 \\ 153 & 44.0 \\ 161 & 44.3 \\ 158 & 44.2 \\ 232 & 44.0 \\ 19 & 40.5 \\ 200 & 44.1 \\ 196 & 44.0 \\ 15 & 42.8 \\ 67 & 43.5 \\ 56 & 43.4 \\ 46 & 42.7 \\ 128 & 43.4 \\ 22 & 42.6 \\ 112 & 44.0 \\ 60 & 44.0 \\ 212 & 44.2 \\ 229 & 44.3 \\ & \\ 133 & 43.6 \\ <0.001 & <0.001 \\ 60 & 1.4 \\ 31.8 & 2.0 \\ & \end{array}$

$\begin{array}{ll}\begin{array}{l}\text { Oil } \\ \text { Yield } \\ (\mathrm{kg}\end{array} & \begin{array}{l}1000 \text { Seed } \\ \text { Weight } \\ \text { ha) }\end{array} \\ & \\ & \\ 106 & 12.00 \\ 101 & 12.02 \\ 70 & 11.29 \\ 67 & 12.04 \\ 64 & 11.99 \\ 104 & 13.14 \\ 9 & 10.43 \\ 94 & 12.28 \\ 88 & 12.22 \\ 6 & 9.76 \\ 28 & 11.86 \\ 22 & 12.07 \\ 20 & 11.15 \\ 53 & 12.20 \\ 7 & 10.45 \\ 53 & 12.25 \\ 27 & 12.25 \\ 87 & 11.99 \\ 109 & 11.31 \\ & \\ 59 & 11.72 \\ <0.001 & <0.001 \\ 21 & 0.66 \\ 21.9 & 3.4 \\ & \end{array}$

